\title{
Consumer acceptance of and willingness to pay for food nanotechnology: a systematic review
}

\author{
Emma L. Giles - Sharron Kuznesof - Beth Clark • \\ Carmen Hubbard $\cdot$ Lynn J. Frewer
}

Received: 14 May 2015/ Accepted: 19 November 2015/Published online: 30 November 2015

(C) The Author(s) 2015. This article is published with open access at Springerlink.com

\begin{abstract}
Consumer's attitudes to, and acceptance of, emerging technologies and their applications, are important determinants of their successful implementation and commercialisation. Understanding the range of socio-psychological, cultural and affective factors which may influence consumer responses to applications of nanotechnology will help "fine-tune" the development of consumer products in line with their expectations and preferences. This is particularly true of applications in the food area, where consumer concerns about technologies applied to food production may be elevated. This research applied systematic review methodology to synthesise current knowledge regarding societal acceptance or rejection of nanotechnology applied to agri-food production. The objective was to aggregate knowledge derived from different research areas to gain an overall picture of consumer responses to nanotechnology applied to food production. Relevant
\end{abstract}

Electronic supplementary material The online version of this article (doi:10.1007/s11051-015-3270-4) contains supplementary material, which is available to authorised users.

E. L. Giles $(\bowtie)$

Health and Social Care Institute, Teesside University, Constantine Building, Middlesbrough,

North Yorkshire TS1 3BA, UK

e-mail: e.giles@tees.ac.uk

S. Kuznesof · B. Clark · C. Hubbard - L. J. Frewer School of Agriculture, Food and Rural Development, Newcastle University, Agriculture Building,

Newcastle upon Tyne, Tyne and Wear NE1 7RU, UK electronic databases of peer-reviewed literature were searched from the earliest date available, for peerreviewed papers which reported primary empirical data on consumer and expert acceptance of agri-food nanotechnology, using a formal systematic review protocol. Inclusion criteria for papers to be included in the review were: empirical peer-reviewed papers written in English; a population sample of adults aged 18 years and over used in the research; a research focus on consumer and expert acceptance of agri-food nanotechnology; and research on attitudes towards, and willingness to pay for, different applications of agrifood nanotechnology. Two researchers independently appraised the papers using NVivo 10 QSR software. Studies examining consumer and expert acceptance were thematically analysed, and key information was collated. The results were synthesised in order to identify trends in information relevant to consumer acceptance of nanotechnology applied to food production. Eight key themes were identified from the 32 papers which were extracted from the literature. These themes were applied to understand the determinants of consumer acceptance of agri-food nanotechnology. Nanotechnology is more likely to be accepted by consumers when applied to development of novel packaging with distinct benefits rather than when integrated directly into agri-food products. Trust and confidence in agri-food nanotechnology and its governance need to be fostered through transparent regulation and development of societally beneficial impacts to increase consumer acceptance. 
Keywords Nanotechnology · Consumer .

Acceptance $\cdot$ Expert opinion $\cdot$ Systematic review

\section{Background}

There has been extensive debate about the potential societal responses to (different) applications of nanotechnology primarily because consumer's attitudes towards, and acceptance of, emerging technologies, and their applications are important determinants of their successful implementation and commercialisation, and without consumer acceptance the potential economic and social benefits of nanotechnology may not be realised (Burri and Bellucci 2008; Frewer et al. 2011; Gupta et al. 2011; Kim et al. 2014; Lowe et al. 1993; Macoubrie 2006; Pidgeon et al. 2011; Renn and Roco 2006; Roco 2003). Stakeholders (drawn from industry and policy communities) have identified applications in the agri-food sector as being the potentially most controversial as far as societal acceptance is concerned (Gupta et al. 2013; Matin et al. 2012). To some extent this reflects expert perceptions that the pattern of societal response to different applications of nanotechnology will be similar to those observed following the introduction of genetically modified (GM) foods (Gupta et al. 2015; Mehta 2004). To date however, there has been little evidence of consumer opposition to agri-food applications of nanotechnology, (George et al. 2014), nor has formalised opposition (for example, through activities linked to pressure groups) been as extensive as that associated with GM foods (Seifert and Plows 2014; van Broekhuizen and Reijnders 2011). It is also important to note that attitudes towards technology are unlikely to remain static in space and time, and the results of a single study are unlikely to reflect an aggregated analysis of multiple studies which use different methodologies, study populations, or applications, and which are embedded in different contexts. The aim of this study was to synthesise current knowledge regarding consumer and expert acceptance or rejection of nanotechnology applied to agri-food production, to identify emerging trends and patterns, and to assess gaps in knowledge.

Whilst there have been systematic reviews of the regulatory situation surrounding nanotechnology (Grobe 2008), to the best of the authors' knowledge, no systematic reviews of research investigating consumer attitudes, perceptions and acceptance of agrifood nanotechnology have been conducted or registered on the PROSPERO ${ }^{1}$ (PROPSERO 2012) database, nor on the databases of the Centre for Reviews and Dissemination (Centre for Reviews and Dissemination 2012; Besley et al. 2008) The systematic reviews that have been conducted to date are in the general area of nanotechnology application (e.g. in relation to risk assessment) or have focused on specific food issues, such as vitamin D food fortification (Black et al. 2011). A systematic review of research into consumer's attitudes towards and acceptance of agri-food nanotechnology is timely and policy relevant, as simply considering attitudes to specific applications may not reflect general trends in attitudes and consumer priorities for development.

This review seeks to synthesise existing knowledge regarding consumer attitudes towards agri-food nanotechnology in order to provide policy makers, nanotechnology experts, and food manufacturers with robust and high-quality evidence concerning consumer acceptance of nanotechnology applied within the agri-food sector. The results can be applied to providing evidence which will assist key stakeholders in their decision making, facilitate fine-tuning of policies and enable an estimation of how consumers may react to future food products, in line with best practices in agri-food technology application (Cook and Fairweather 2007; Raley et al. 2015).

\section{Methods}

A protocol (see Supplementary Data 1) for the review was compiled in full before searching commenced, and there were no substantive variations from protocol during the course of the study. Reporting of the review follows the Preferred Reporting Items for Systematic

\footnotetext{
${ }^{1}$ Prospero is a well-known database of systematic reviews in health and social issues, ran by the CRD. The CRD produces three databases: Database of Abstracts of Reviews of Effects; NHS Economic Evaluation Database; and Health Technology Assessment Database. Whilst these databases are not wholly applicable to our review, they are the only databases of their kind to register systematic reviews, and thus were checked for thoroughness. Any other systematic reviews on a similar topic would have been returned in our searches of the main databases for relevant papers.
} 
Reviews (PRISMA checklist; Fig. 1) guidelines (see Supplementary Data 2: Moher et al. 2009).

\section{Information sources}

Seven electronic databases of peer-reviewed literature were searched from the earliest date available (indicated in brackets) to October 2015. These were CAB Abstracts (1910), EBM Reviews (1991), Embase (1980), Medline (1946), PsycINFO (1806), Scopus (1960) and Web of Science (1864). The search strategy combined relevant terms for 'nanotechnology', 'food' and 'consumer acceptance', and search strings were adapted as appropriate for each database. Examples of the search terms used are provided in Supplementary Data 3. Additionally, reference lists of all papers meeting the inclusion criteria were also reviewed, and citation searches of included papers were conducted using Web of Science. Endnote X6 was used to manage search results, with NVivo 10 QSR International software subsequently used for data analysis.

\section{Eligibility criteria}

Studies deemed eligible for inclusion were papers which reported primary empirical data on consumer and expert acceptance of agri-food nanotechnology. Only peer-reviewed papers, written in English, were included in this review in order to focus on highquality evidence on the acceptance of agri-food nanotechnology. The inclusion criteria are fully described in Table 1 and were established to answer the primary research question: How acceptable is nanotechnology to consumers and experts when applied to agri-food products?

Study selection, appraisal and synthesis

Papers were screened by two independent researchers (ELG and BC) in a three-stage process in relation to the eligibility criteria. This was done at title, abstract and full text level. Any disagreements were resolved by face-to-face discussion. Due to reference lists and citation searches being conducted, some studies were included which contained the same population as previous studies (Brown et al. 2015; Yue et al. 2015b; Roosen et al. 2011). Where studies report the same data, they are only reported once in the result i.e. there are 32 papers but only 29 stand-alone studies.

Quality assessment of included studies was carried out independently by two researchers (ELG \& BC) with the Critical Appraisal Skills Programme Qualitative Research Checklist (Critical Appraisal Skills
Fig. 1 PRISMA flow diagram

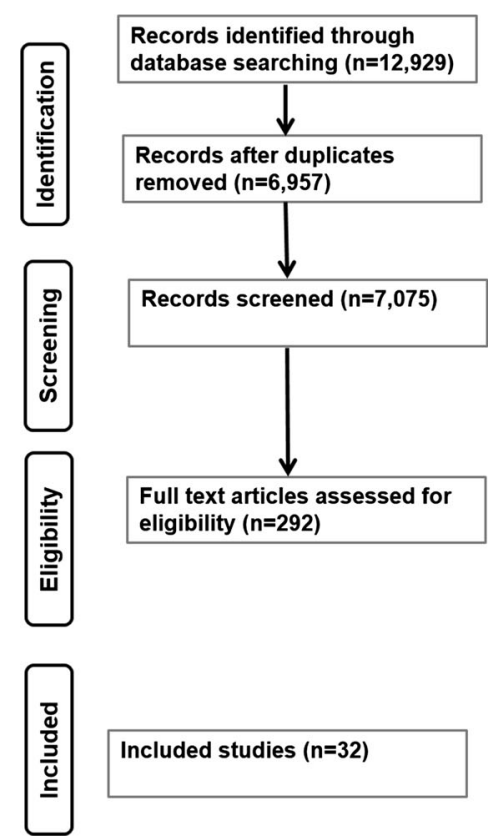

Records excluded ( $n=6,783)$, on title $\&$ abstract screening

Full text articles excluded $(n=260)$, where the paper:

- Was not empirical ( $n=143)$

- Did not use a sample of adults aged $18+(n=2)$

- Did not focus on acceptance of food nanotechnology ( $n=62)$

- Did not discuss willingness to pay for food nanotechnology $(n=30)$

- Unavailable $(n=17)$

- Not a peer reviewed journal paper $(n=5)$

- Included in main sifting $(n=1)$ 
Table 1 Inclusion criteria

\begin{tabular}{ll}
\hline Study component & Inclusion criteria \\
\hline Date range & All dates \\
Publication characteristics & English language, peer-reviewed journal article \\
Study design & Empirical, qualitative and/or quantitative primary data \\
Population & Adults aged 18 years and over \\
Focus & Must contain a discussion of consumer acceptance of food nanotechnology \\
Outcome & Must contain discussion of willingness to pay/intention to pay for food nanotechnology products \\
\hline
\end{tabular}

Programme 2013) used to assess qualitative research. To assess the quantitative papers, the survey research tool by Petticrew and Roberts (2006) was used. For the mixed methods papers, both tools were used for quality appraisal. Disagreements were resolved through discussion (ELG \& BC).

The studies examining consumer and expert acceptance are presented in a tabular summary for narrative synthesis (see Table 2). They are described in terms of their aims, methods and study participants along with a brief summary of their key findings. Due to the plethora of findings, inconsistency in reporting styles and complexity and mixed methods nature of the data, studies were deemed too heterogeneous for metaanalysis, a four-stage thematic analysis approach was taken (Braun and Clarke 2006).

The first stage involved reading through the papers line-by-line and highlighting relevant data (e.g. a word or a paragraph), to which a code was assigned. These codes were either sociologically constructed. This means that a code was given to the data by the researchers (ELG and BC), which was either a word, sentence or paragraph, and which best reflected the meaning within the data (e.g. safety, lack of testing, too expensive) — or an 'in vivo' code — a code which directly copies what was published in the text (Barnett-Page and Thomas 2009). The second stage of the coding process involved examining these initial codes to ensure all data had been thematically analysed (by ELG and BC). The third stage involved sorting the initial codes into broader categories. Here, the researchers (ELG and BC) reflected upon the array of codes and generated broader categories by merging some codes with others, creating new codes, or renaming or deleting existing codes. The fourth stage involved assigning several themes, which essentially grouped the initial codes into major themes that would help address the research questions. Memo notes were made on how and why these analytical codes were generated by one researcher (ELG), with two further researchers (BC and SK) verifying them. These themes are presented in Table 5, and are discussed in the next section. They are illustrated using representative quotations to illustrate each theme.

\section{Results}

Thirty two papers were included; six qualitative studies (Becker 2013; Brown et al. 2015; Brown and Kuzma 2013; Gupta et al. 2012; Gupta et al. 2015; Köhler and Som 2008), 23 quantitative studies (surveys and experiments) (Besley et al. 2008; Bieberstein et al. 2013; Capon et al. 2015; Casolani et al. 2015; Cobb and Macoubrie 2004; Conti et al. 2011; Cook and Fairweather 2007; Farshchi et al. 2011; Groves 2013; Gupta et al. 2013; Marette et al. 2009; Roosen et al. 2015; Roosen et al. 2011; Schnettler et al. 2013a; Schnettler et al. 2014; Schnettler et al. 2013b; Siegrist et al. 2007; Siegrist et al. 2009; Siegrist et al. 2008; Stampfli et al. 2010; Suhaimee et al. 2014; Yue et al. 2015a, b) and three mixed methods papers (Handford et al. 2015; Simons et al. 2009; Yawson and Kuzma 2010) (see Table 2). During sifting, 17 papers were excluded because they were unavailable from Newcastle University, the Internet or through inter-library loans, or they were unobtainable in English (Ahmadi and Ahmadi 2013; Cheng et al. 2009; Lin et al. 2011; Militaru and Ionescu 2013; Mir 2007; Rakia 1993; Rogers et al. 2013; Schiffeler 2014; Scholl 2013; Siegrist 2007; Stone 2009; Suerdem et al. 2013; Tanaka 1995; Teggatz 2013; Thoenes 1982; Thompson n.d.; Zimmer 2008), but which may have been potentially relevant. The qualitative empirical papers 


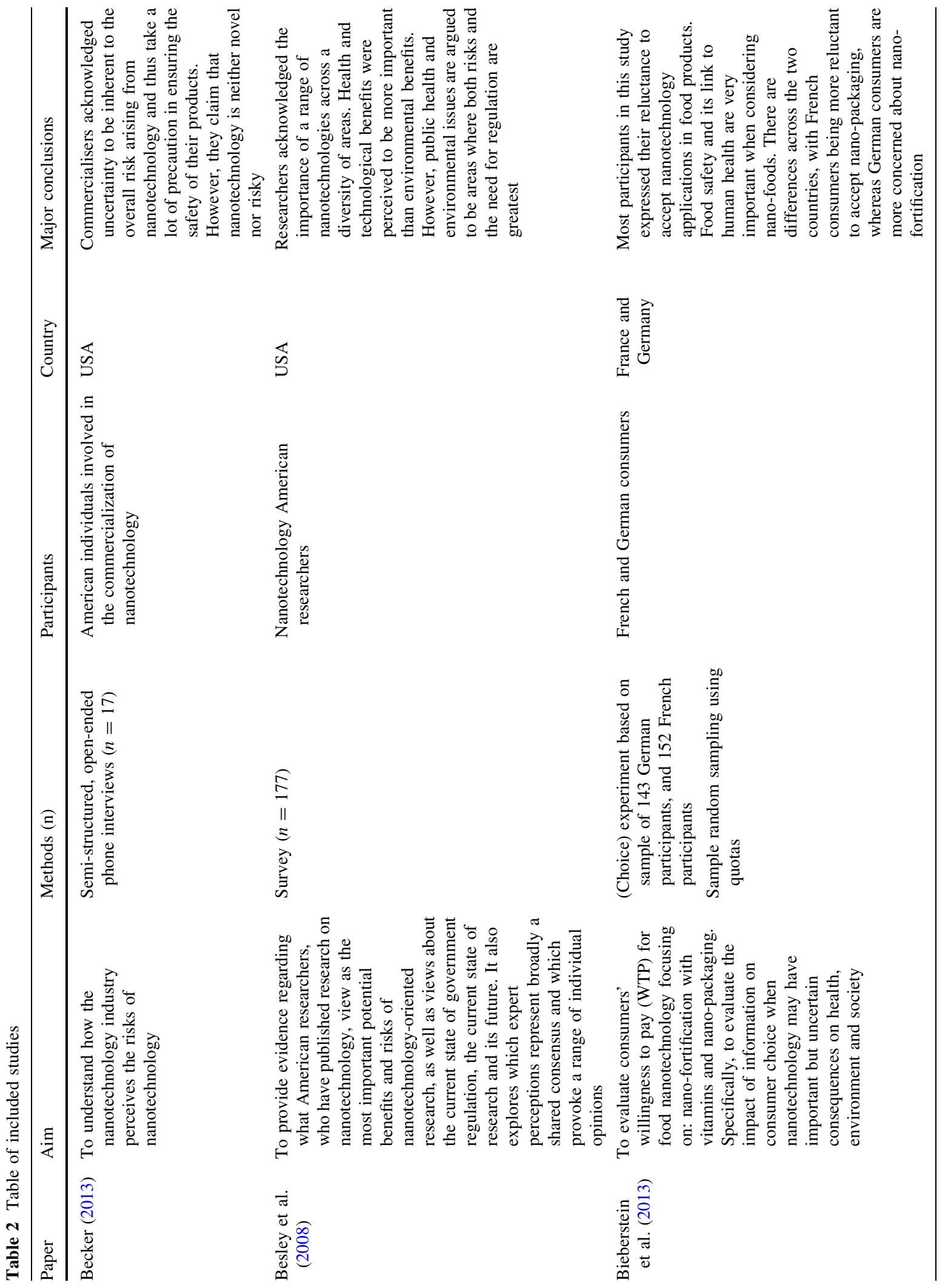




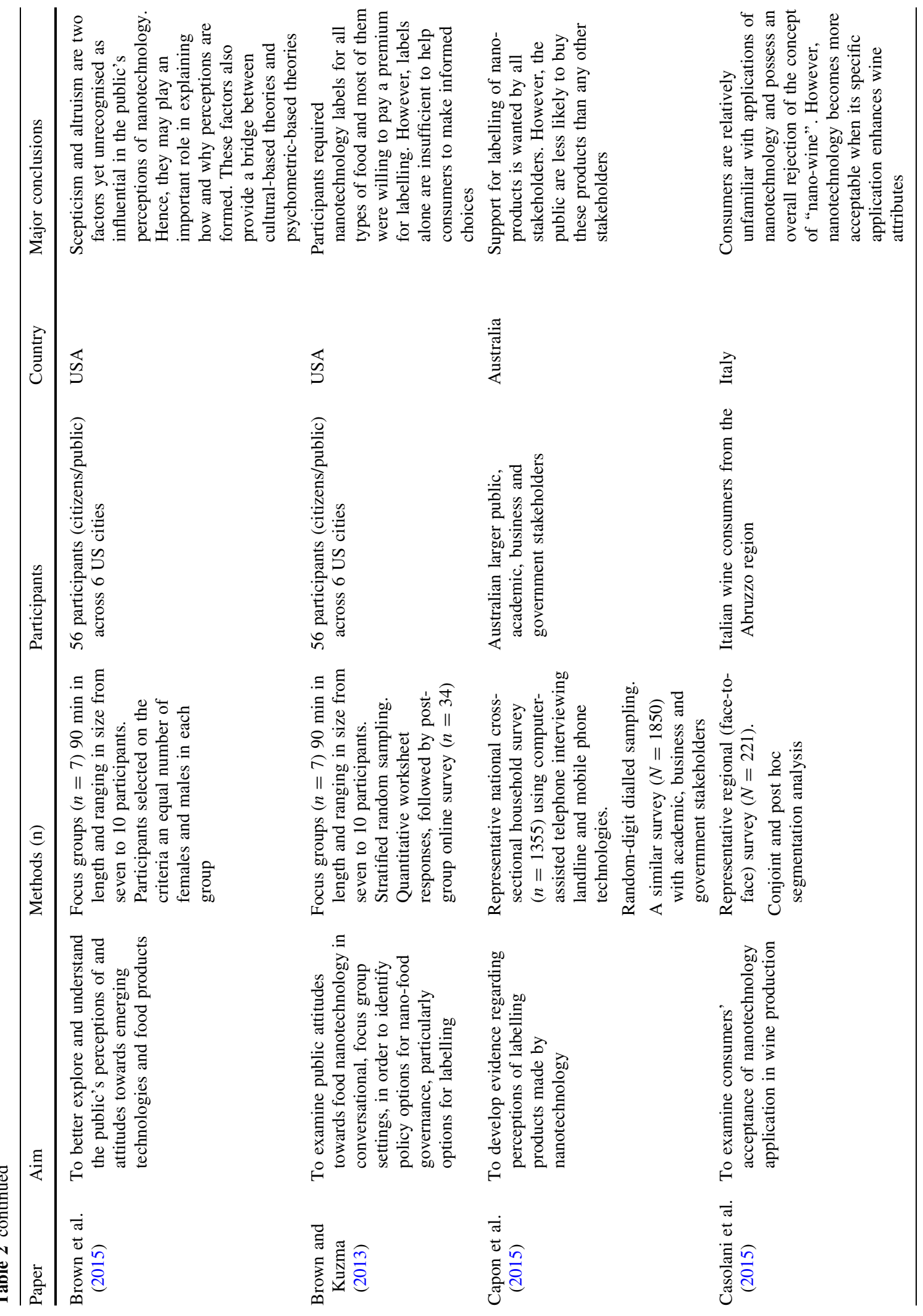




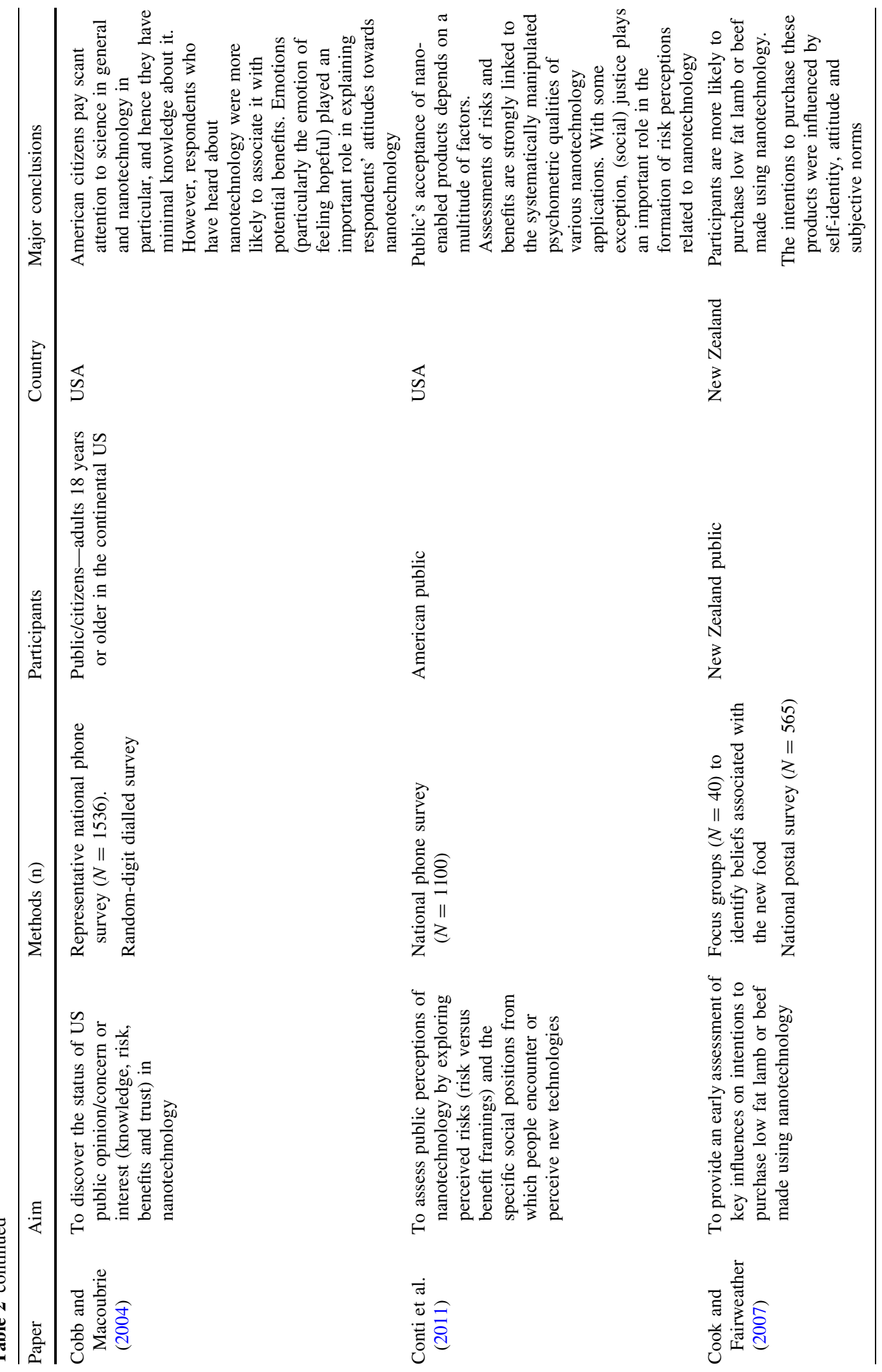




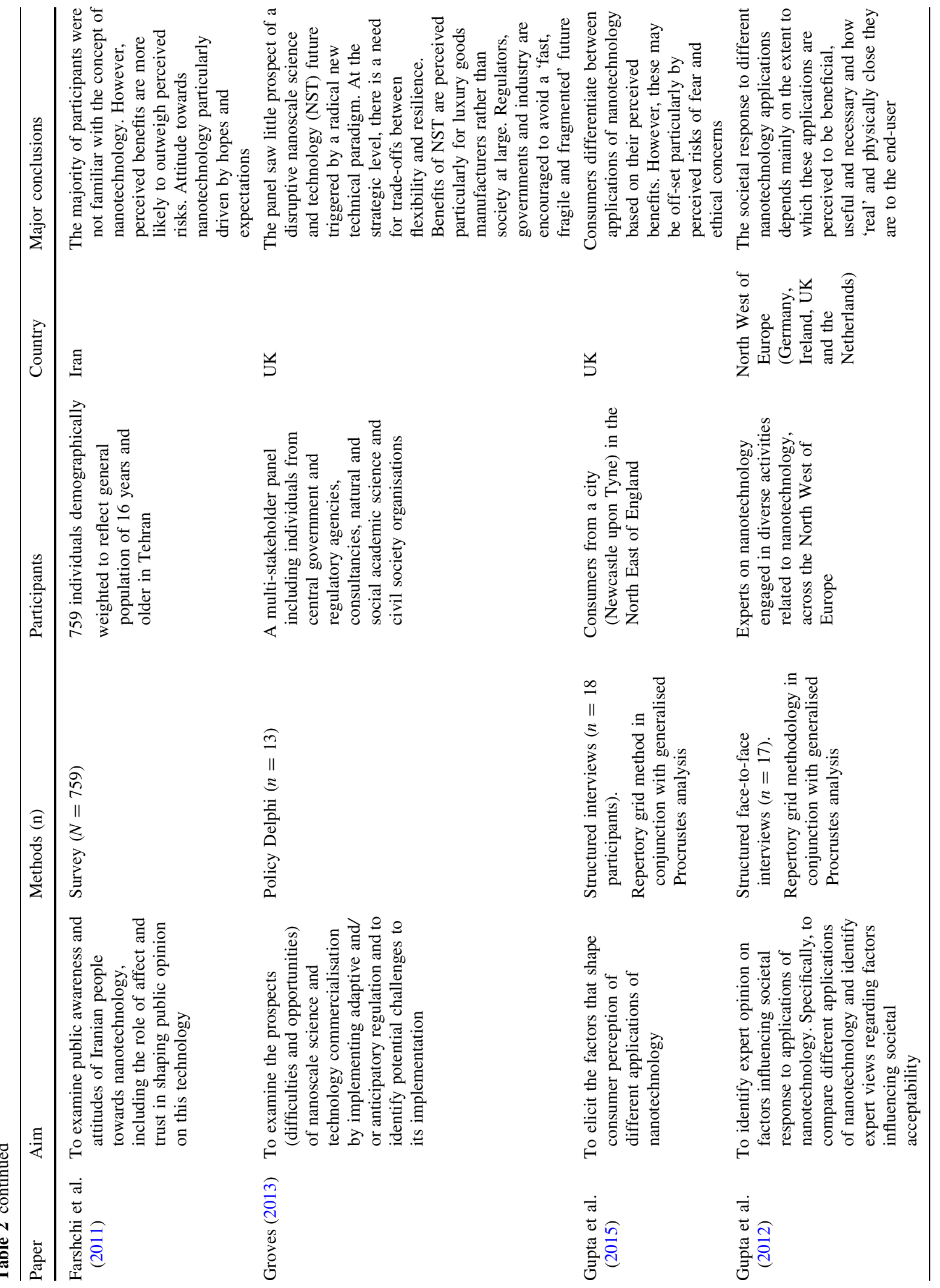




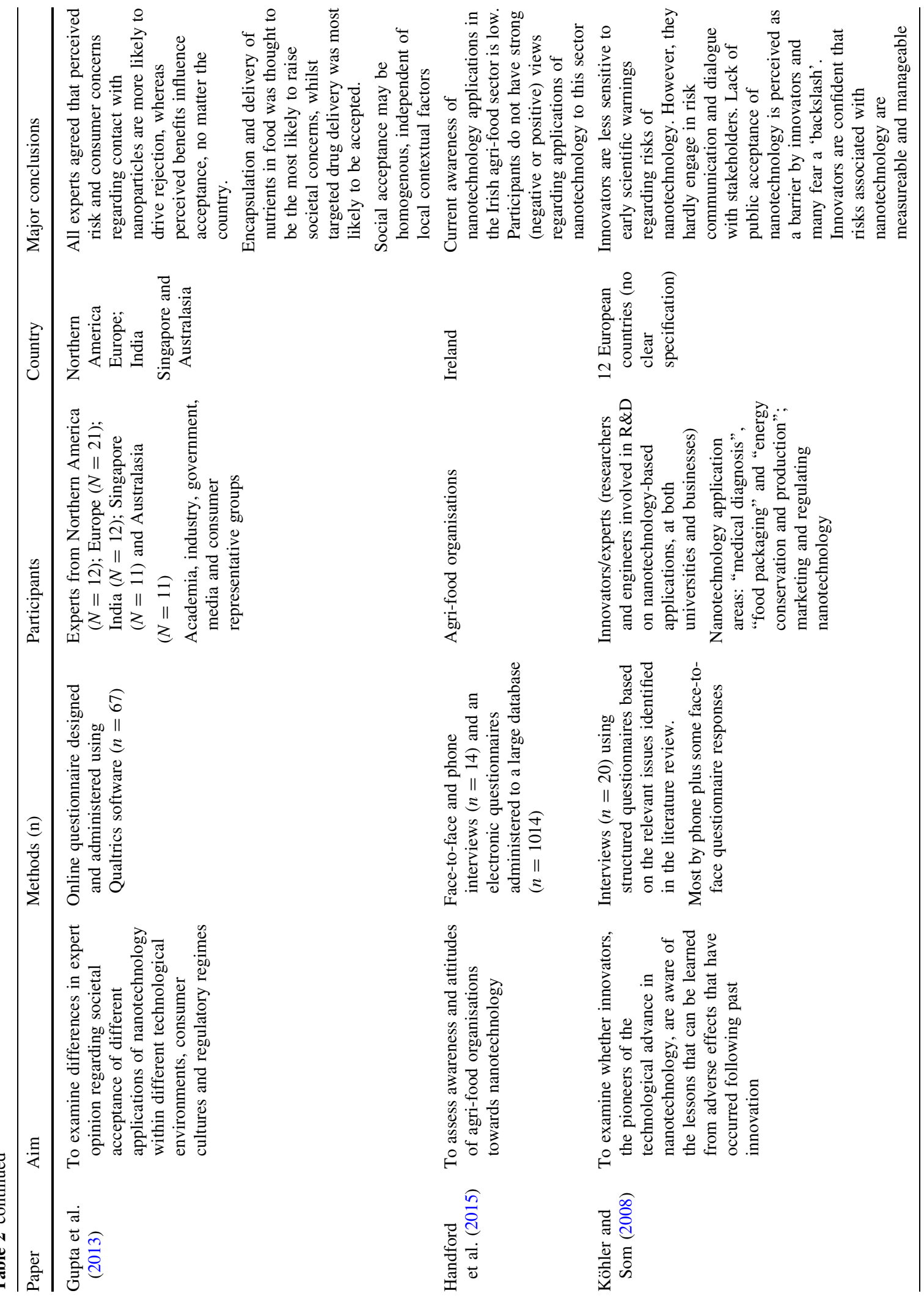




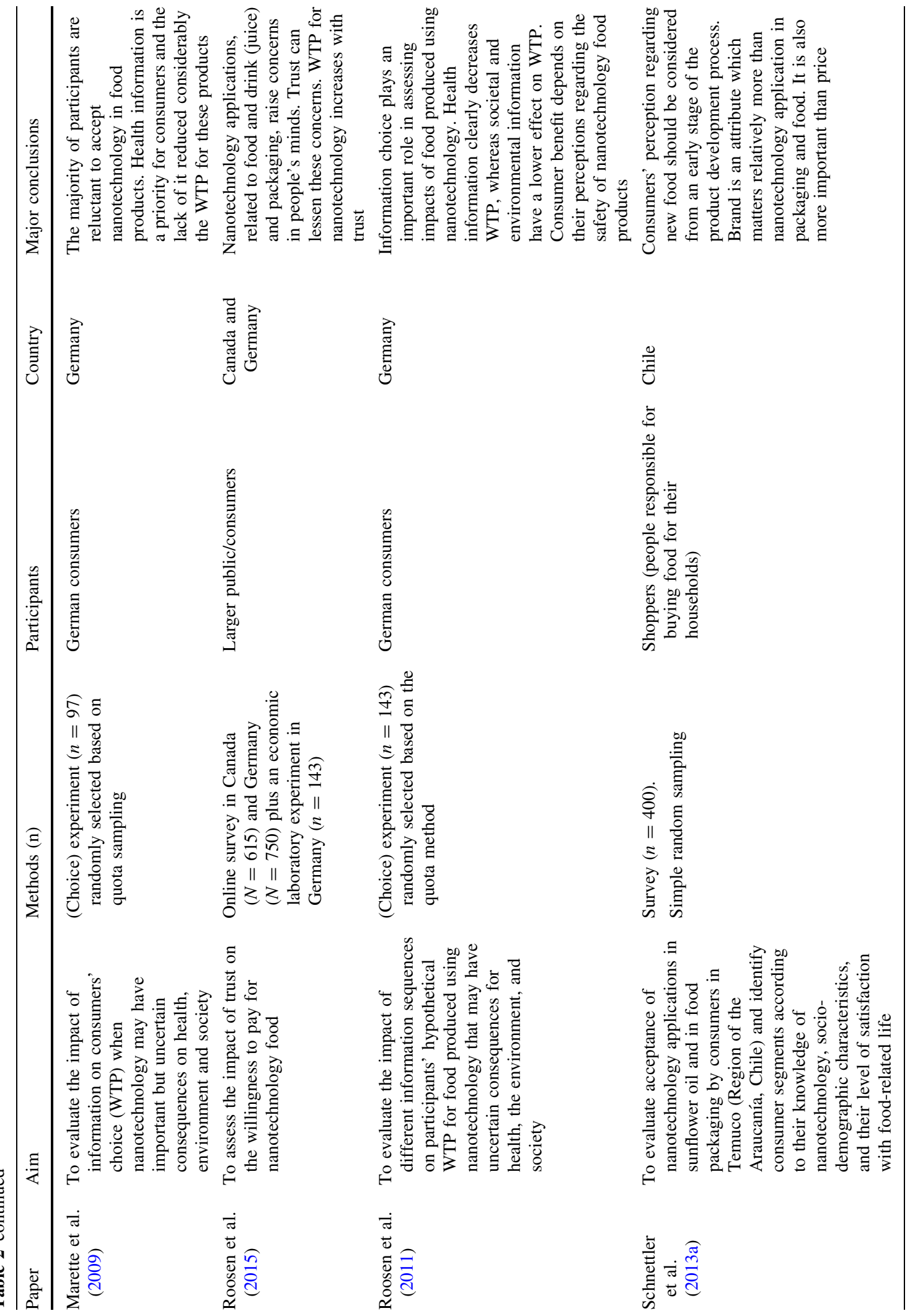




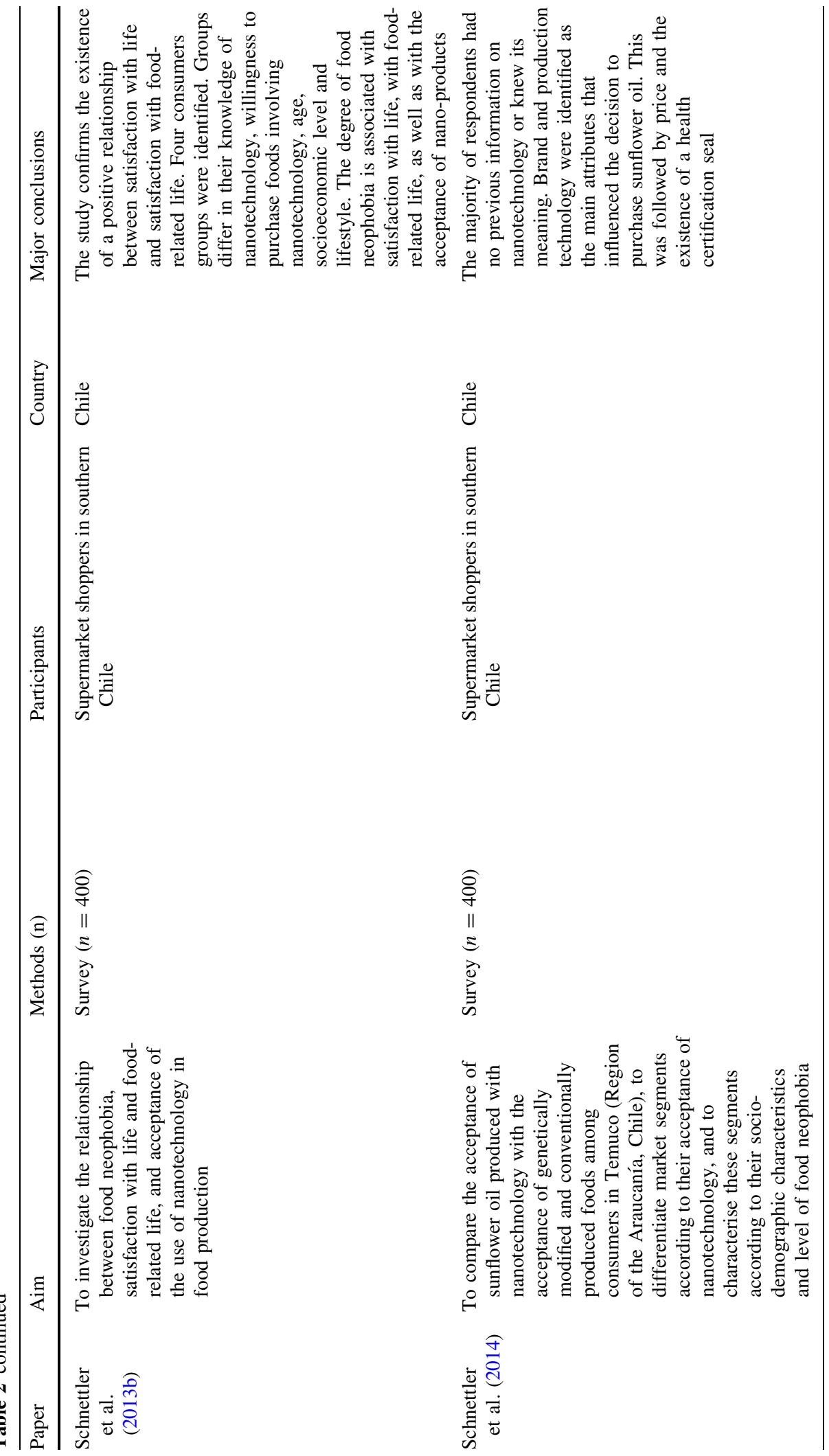




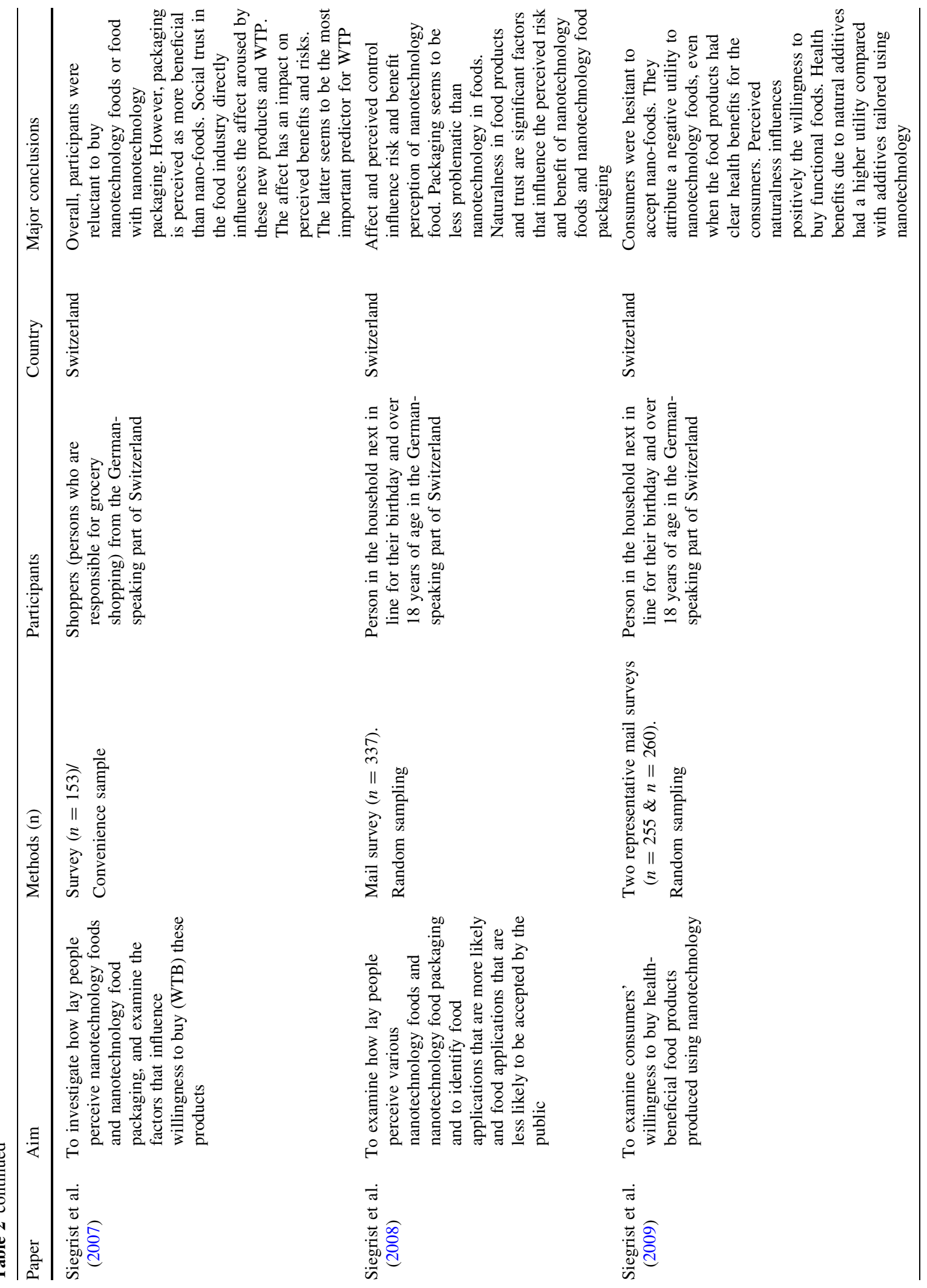




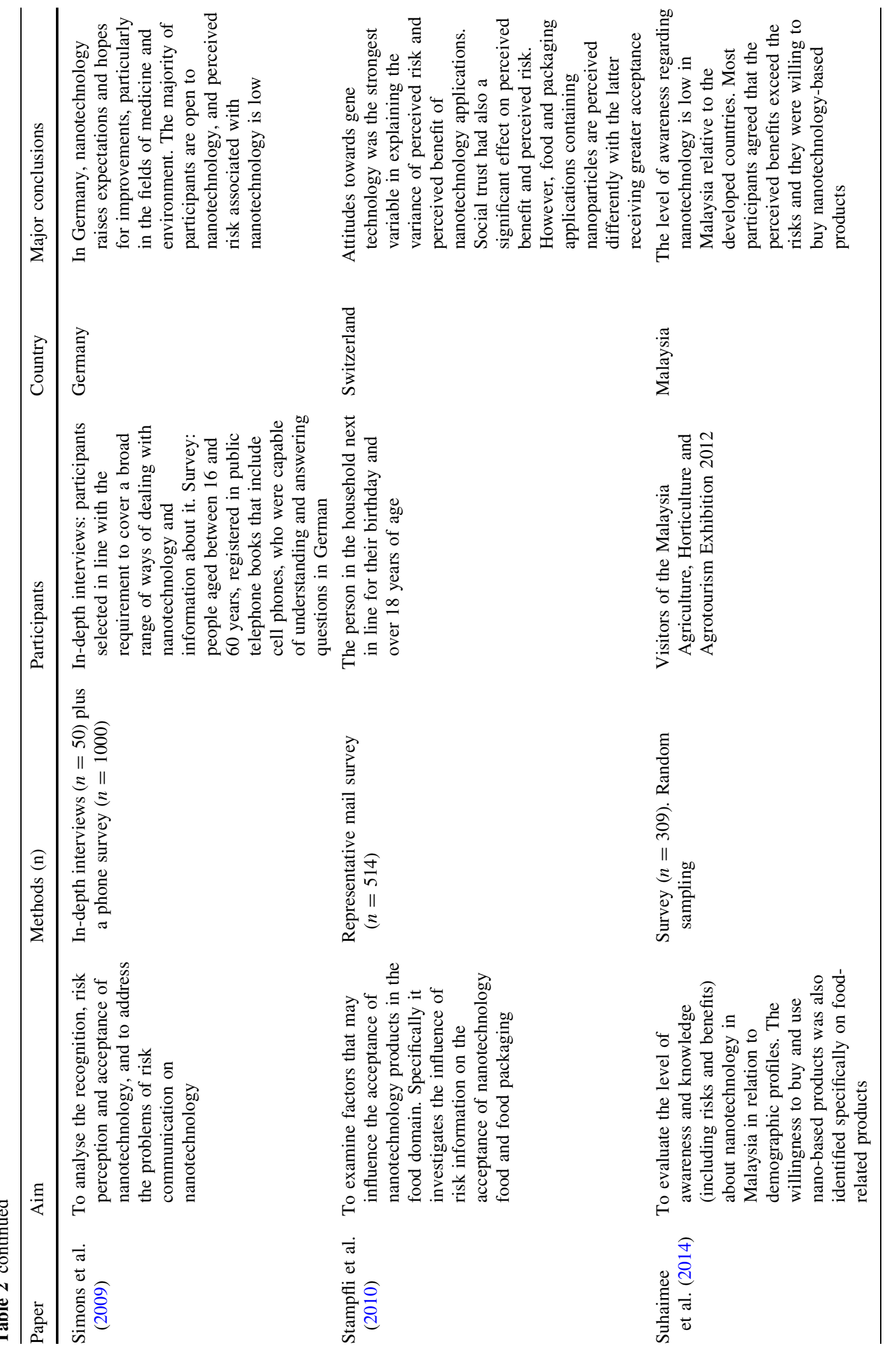




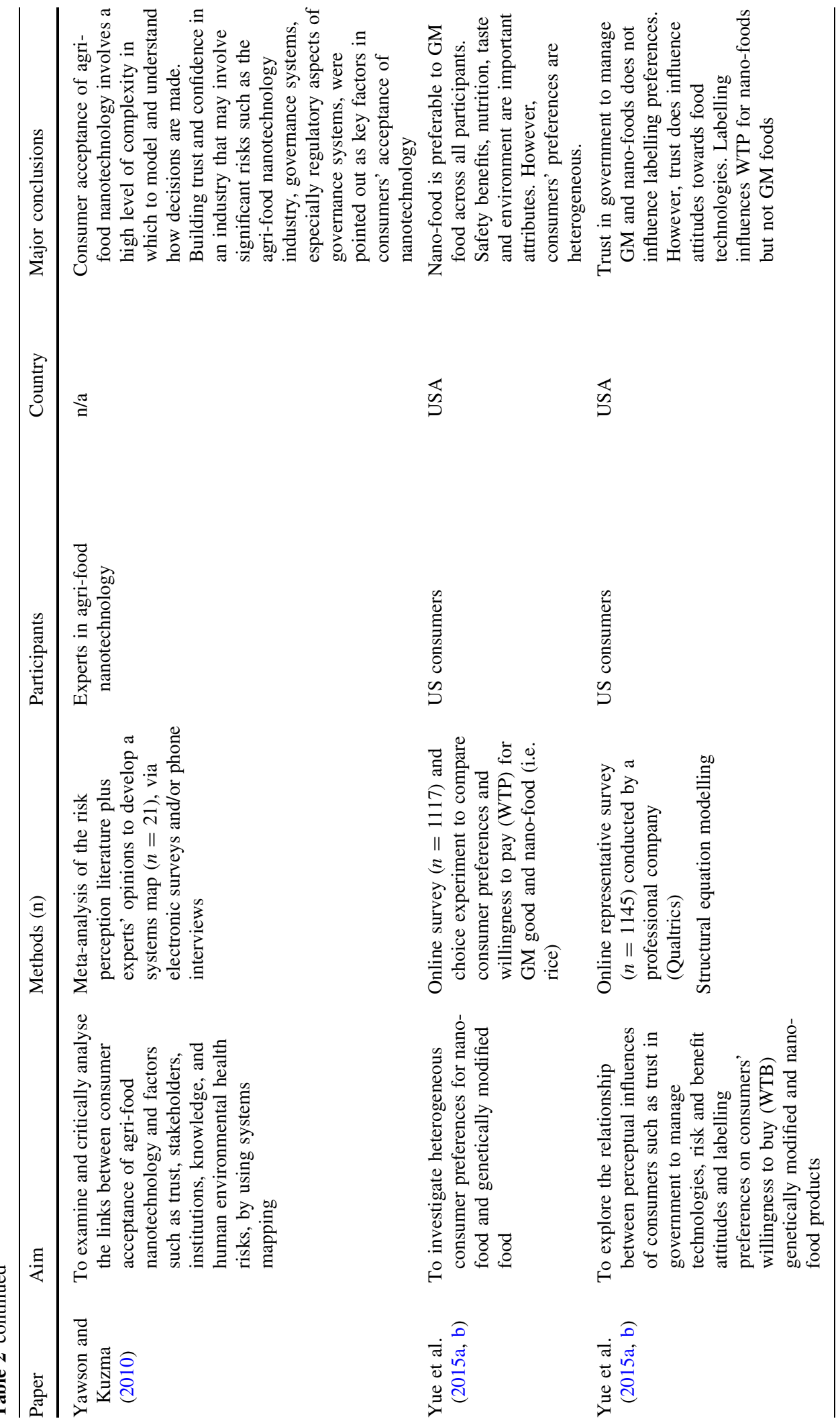


collected data using focus groups $(n=2)$ (Brown et al. 2015; Brown and Kuzma 2013) and interviews $(n=4)$ (Becker 2013; Gupta et al. 2012; Gupta et al. 2015; Köhler and Som 2008). The quantitative empirical papers largely utilised survey methodology $(n=20)$ (Besley et al. 2008; Capon et al. 2015; Casolani et al. 2015; Cobb and Macoubrie 2004; Conti et al. 2011; Cook and Fairweather 2007; Farshchi et al. 2011; Gupta et al. 2013; Roosen et al. 2015; Schnettler et al. 2013a, b; Schnettler et al. 2014; Siegrist et al. 2007; Siegrist et al. 2009; Siegrist et al. 2008; Stampfli et al. 2010; Suhaimee et al. 2014; Yue et al. 2015a, b), one used a survey as part of a Delphi methodology (Groves 2013), and a further three used experiments (Bieberstein et al. 2013; Marette et al. 2009; Roosen et al. 2011). The mixed methods studies combined a survey and interview methods approach (Handford et al. 2015; Simons et al. 2009; Yawson and Kuzma 2010). Study populations were mainly individual members of the public (consumers/shoppers) $(n=23)$ (Bieberstein et al. 2013; Brown et al. 2015; Brown and Kuzma 2013; Casolani et al. 2015; Cobb and Macoubrie 2004; Conti et al. 2011; Cook and Fairweather 2007; Farshchi et al. 2011; Gupta et al. 2015; Marette et al. 2009; Roosen et al. 2015; Roosen et al. 2011; Schnettler et al. 2013a; Schnettler et al. 2014; Schnettler et al. 2013b; Siegrist et al. 2007; Siegrist et al. 2009; Siegrist et al. 2008; Simons et al. 2009; Stampfli et al. 2010; Suhaimee et al. 2014; Yue et al. 2015a, b), 'experts' in the area of nanotechnology $(n=6)$ (Besley et al. 2008; Groves 2013; Gupta et al. 2013; Gupta et al. 2012; Köhler and Som 2008; Yawson and Kuzma 2010), agri-food organisations (Handford et al. 2015), 'commercializers' (individuals who make deliberate efforts to increase the presence of products on the market that employ nanotechnology or contain nanomaterials"(Becker 2013); and one study surveyed consumers, academic, business and government stakeholders (Capon et al. 2015).

Quality appraisal of the qualitative studies is shown in Table 3, and the quantitative studies in Table 4. For the qualitative studies, all six papers included a clear statement of the aims of the research and employed a qualitative methodology. The majority of studies had designs appropriate to the aims and objectives, used a suitable recruitment strategy, collected data in a way that was appropriate to the research topic and provided a clear statement of findings. However, the majority of studies did not consider the impact of the relationship between the researcher and the participants, and only two of them explicitly state how they had considered ethical issues. For the experimental studies, a lack of information reported in the papers meant that many study attributes were rated as 'unclear', most likely due to reporting restrictions in the respective journals. Finally, for one of the qualitative studies, information to demonstrate the rigour of the data analysis was not provided. All quantitative studies employed a methodological approach appropriate to the research topic and most undertook appropriate analyses, with the remaining four being unclear as to exactly how they analysed the data. However, for the majority of the studies it was not possible to determine whether a representative sample and objective measures (e.g. validated survey questions) had been used, with only studies, typically the experimental ones, using quota sampling to ensure samples were representative. Less than half of the studies justified their sample size or reported the response rate during recruitment. Finally, in terms of the quality of the papers, it may be that key methodological issues were not reported, rather than these being weak areas of study design, although this is potentially interpretable as evidence of bias. In the absence of validated quality appraisal tools, a best match was used.

The results below present the main themes that were identified from the thematic analysis (see Table 5). We indicate the relevant supplementary data boxes which are pertinent to each theme throughout the next section.

Theme 1: type and applications of agri-food nanotechnology

Nanotechnology can be integrated into food products, can form part of the packaging of food, and/or can be used when processing food products. When considering these three types of application, overall, the majority of the studies (regardless of sample population) reported greater consumer acceptance of nanotechnology when it was applied to agri-food packaging and processing activities, compared to when it was integrated into agri-food products (see Supplementary Box 1).

Both consumer and expert opinion were divided on whether they found nanotechnology to be acceptable or unacceptable when used directly in foods as such. Experts appear to rate nanotechnology when 
$467 \quad$ Page 16 of 26

J Nanopart Res (2015) 17:467

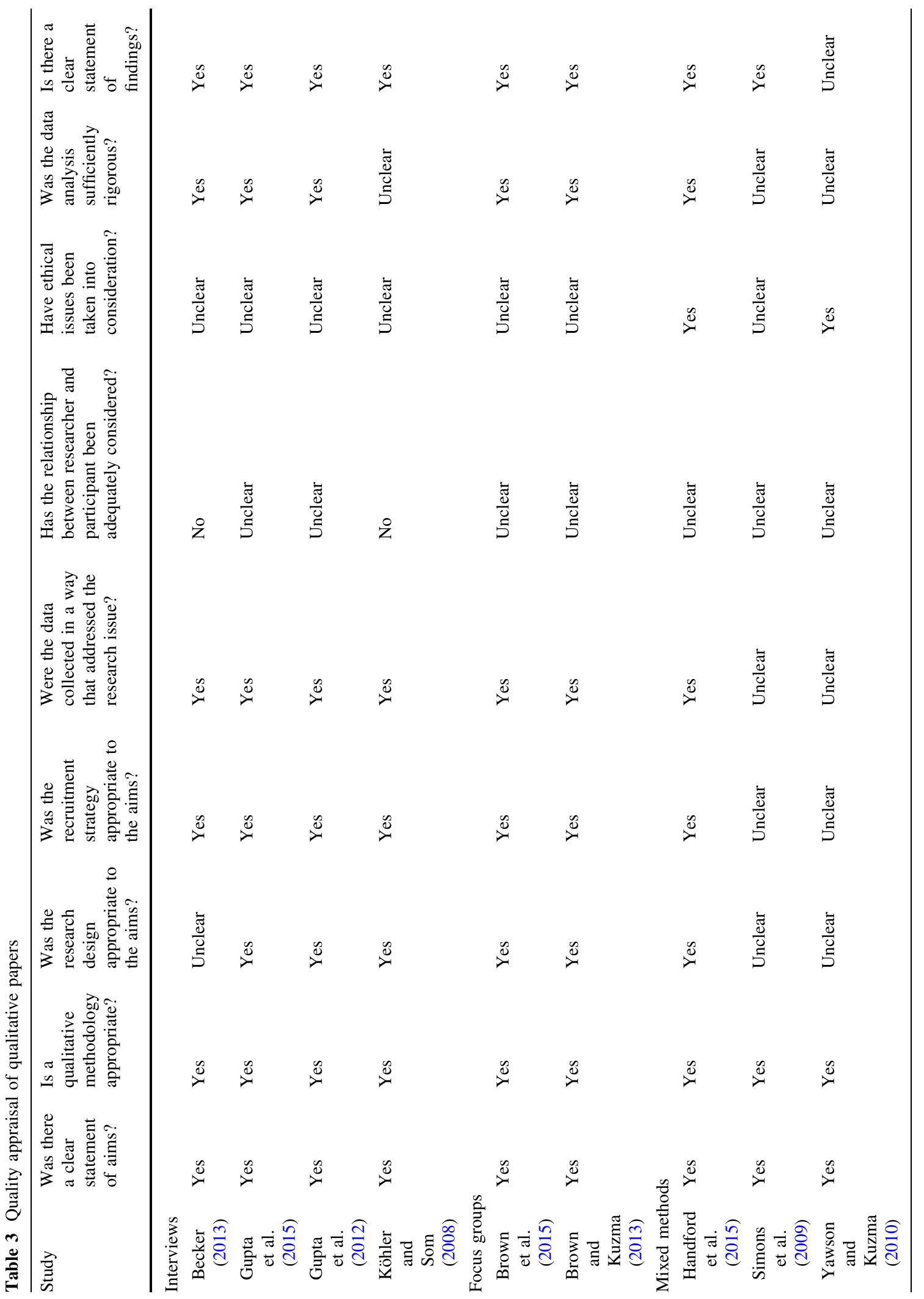

Springer 
J Nanopart Res (2015) 17:467

Page 17 of $26 \quad \mathbf{4 6 7}$

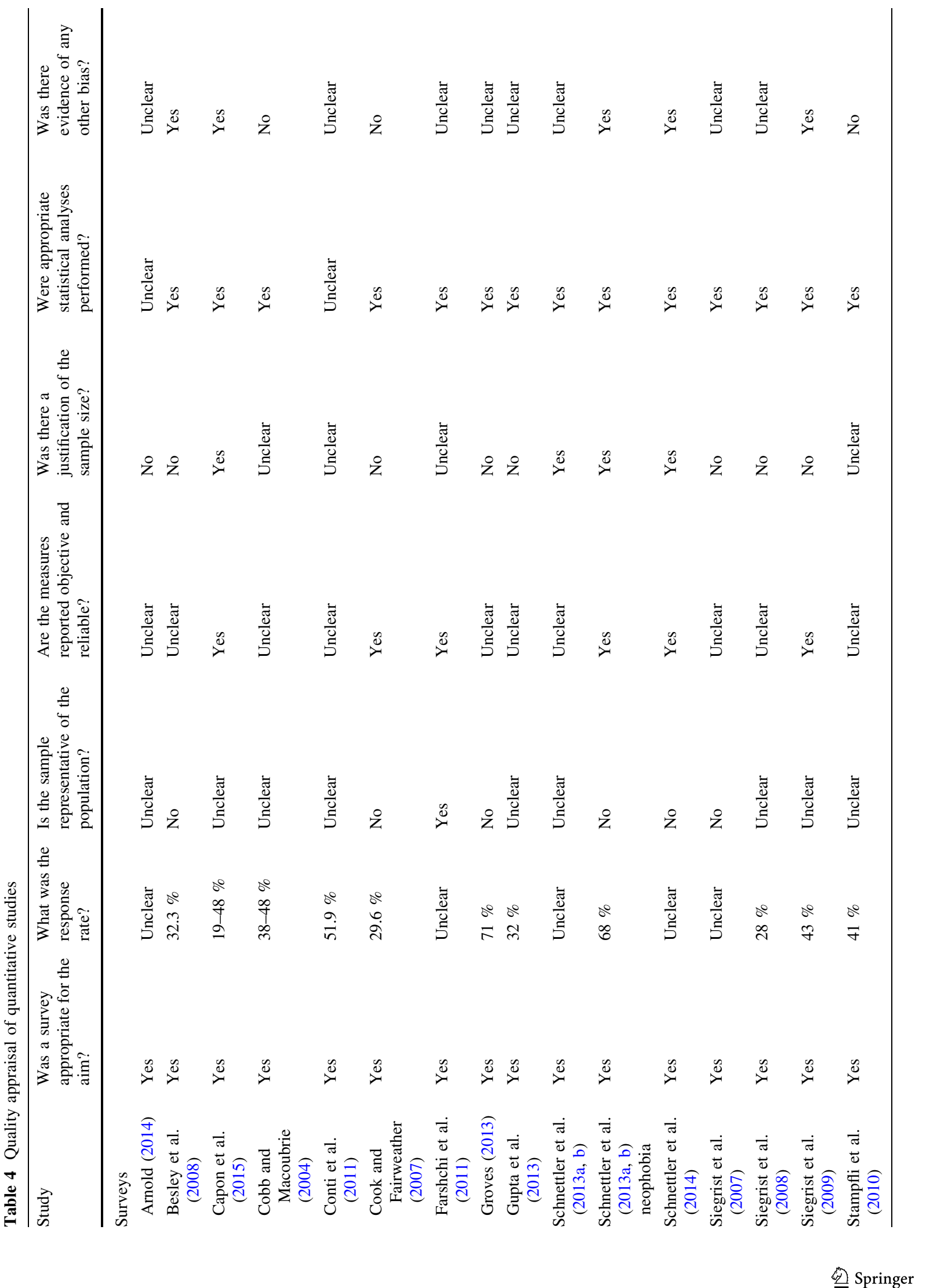


467 Page 18 of 26

J Nanopart Res (2015) 17:467

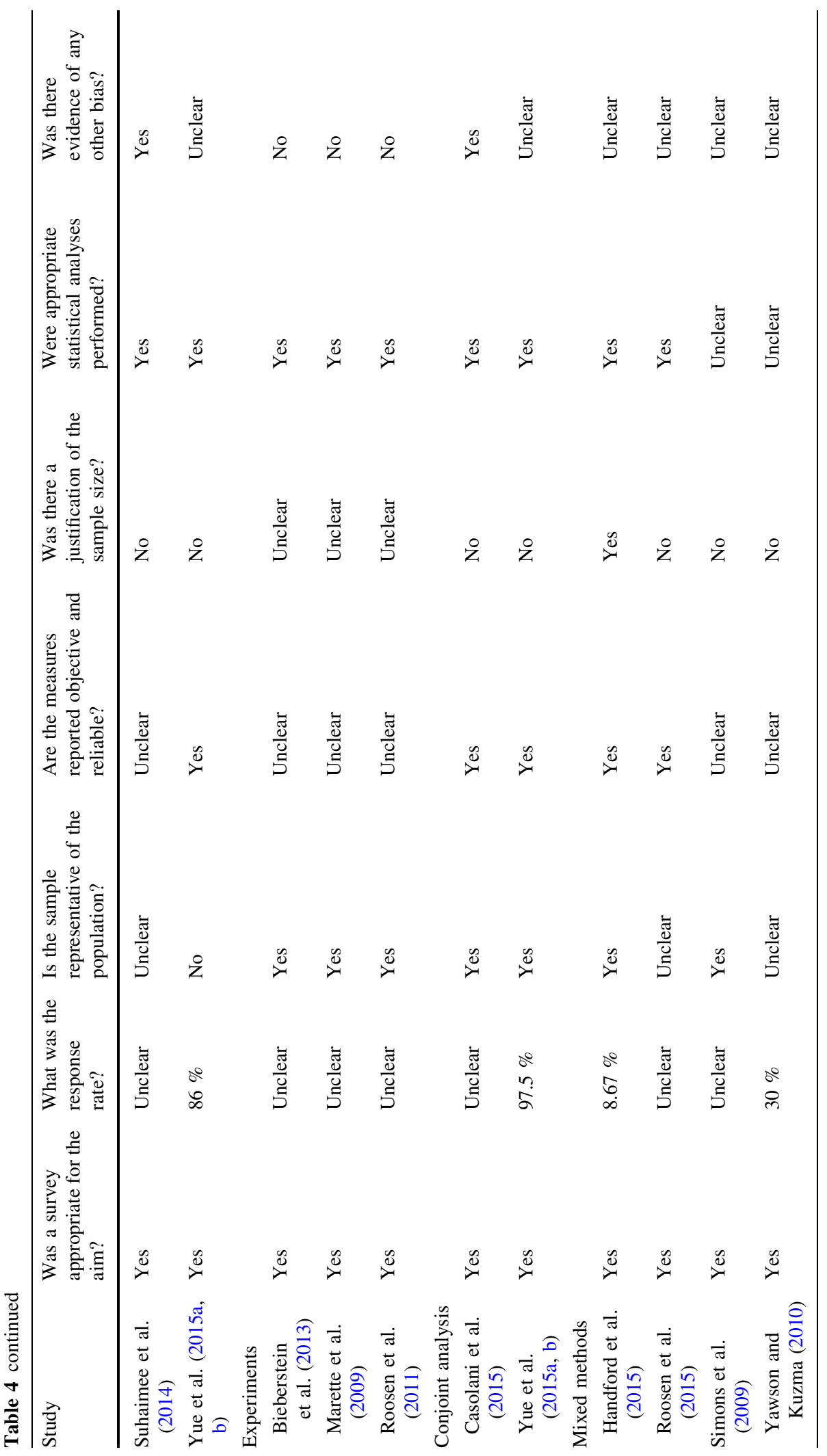

Springer 
Table 5 Analytical themes

\begin{tabular}{ll}
\hline Theme 1 & Type and applications of food nanotechnology \\
Theme 2 & Benefits and risks of food nanotechnology \\
Theme 3 & Socio-demographic influences \\
Theme 4 & Creating an informed and trusting consumer \\
Theme 5 & Characteristics of food nanotechnology \\
Theme 6 & Link to historical agri-food technology concerns \\
Theme 7 & Marketing and commercialisation \\
Theme 8 & Future applications of agri-food nanotechnology
\end{tabular}

applied to food and food products to be more acceptable than do consumers, but that could be because many of these experts worked in the nanotechnology field hold some asymmetric information (i.e. greater knowledge and information about risk and benefit assessment which is not available to consumers).

Theme 2: benefits and risks of agri-food nanotechnology

Often agri-food-related nanotechnology was considered acceptable by experts when clear benefits could be identified. Experts considered benefits in relation to food freshness and safety, and wider environmental and food manufacturing advantages. In particular, if nanotechnology could prevent food spoilage and enhance the shelf-life of the food, and reduce the amount of packaging that would need to be used, it was viewed as acceptable. Additional wider applications of nanotechnology included using nanotechnologies to reduce food shortages, and to improve (reduce) calorie content of food. Ultimately, if the perceived benefits were thought to outweigh the perceived risks then nanotechnology applied to agri-food production was acceptable (see Supplementary Box 2a).

The available evidence suggests that consumers view agri-food nanotechnology favourably, for example in comparison to other agri-food technology innovations recently introduced such as genetically modified (GM) foods. Moreover, if the technology results in cheaper consumer products, and when it could assist beneficial food modifications (such as improved taste and disease prevention), it was perceived as acceptable. As found in the expert studies, the consumer studies found that if the perceived benefits outweighed the perceived risks, then agri- food nanotechnology is more acceptable to consumers (see Supplementary Box 2b).

The 'commercializers' perceived agri-food nanotechnology to be societally acceptable, although this may be attributable to participant's professional roles in promoting such products (see Supplementary Box 2c). Ultimately, commercialisers viewed agrifood nanotechnology to be novel, to pose a low risk to individuals in terms of health impacts, and to be societally acceptable given that there are "riskier" technologies within the marketplace (although it was not clear to which 'riskier' technologies participants were referring in the published research).

However, both experts and consumers expressed concerns about the potential risks associated with using nanotechnology to produce food and food products. Experts perceived a greater risk associated with nanotechnology applied to the production of food products directly as compared to food packaging (see Supplementary Box 2d).

Experts and commercialisers noted that, even when nanotechnology was used in food packaging, there may be the potential for it to contaminate food with which it came into contact, increasing risks to consumers (see Supplementary Box 2e). The proximity of nanoparticles to the human body, and in particular ingestion of the particles, was viewed as high risk, and hence unacceptable by some experts.

Within the consumer studies, multiple concerns were raised. These included concerns about potential side effects, and beliefs that the technology could be misused; both of these concerns were underpinned by a fear of the unknown (see Supplementary Box 2f). Agri-food nanotechnology was also considered to be unacceptable because foods containing the technology are not perceived to be "natural" products. There was also a concern that nanotechnology is used for increasing profit, rather than for producing improved food products with discrete consumer benefits.

Theme 3: socio-demographic influences

The studies included in the review are heterogeneous in nature and so it is difficult to conclusively link opinions about agri-food nanotechnology to individual socio-demographic characteristics. However, there is some indication that certain population groups may be more accepting of agri-food nanotechnology than others (see Supplementary Box 3). In particular, white, 
male population groups perceive fewer risks to be associated with the application of nanotechnologies. In terms of expert opinion regarding perceived acceptance, Europeans and Australasians appeared to be less open to agri-food nanotechnology than other population groups. In addition, those who are traditional in their outlook may perceive greater risks to the use of agri-food nanotechnologies, compared to those who are open to new technologies. However, in most of these studies no explanation was provided to explain how and why these particular socio-demographic groups may influence levels of consumer acceptance of agri-food nanotechnology.

Theme 4: creating an informed and trusting consumer

The available evidence suggests that consumer acceptance of agri-food nanotechnologies may increase if there is clarity regarding who takes responsibility for creating and regulating safe nanotechnology products, as well as regarding who provides information about safety to the general public (see Supplementary Box 4a). Although regulations regarding the protection of human health is an obvious requirement for the effective commercialisation of any agri-food technologies, participants indicated that (harmonised) regulations are also required to facilitate trade of food products developed using nanotechnology across countries (see Supplementary Box 4b). Whether or not information should be provided through product labels, to inform consumers that particular products have been produced using nanotechnology, was a more contentious issue. It is unclear how much information consumers should be provided with, nor who should be responsible for educating and informing consumers about agri-food nanotechnology (see Supplementary Box 4c). Underpinning consumer acceptance (or rejection) of foods made using nanotechnology was the issue of trust. There is evidence that a higher level of trust in the nanotechnology industry was linked to greater acceptance of the technology (see Supplementary Box 4d). Consumers place a greater degree of trust in nanotechnology when it was used in food packaging compared to when it is integrated into food products.

Many studies indicated that consumers have limited knowledge about nanotechnology and how it can be applied to food products. For some consumers this may encourage early adoption of the technology, for others it can create concerns. Low levels of knowledge about nanotechnology may translate into a lower willingness to accept and purchase agri-food nanotechnology products because of a lack of understanding of how it is used in the food (see Supplementary Box 4e).

Commercialisers recognised that, in order to increase consumer acceptance of, and trust in, agrifood nanotechnology, rigorous testing of products may have to be undertaken by companies who use nanotechnology in their products (see Supplementary Box 4f). Being prepared for regulatory and labelling changes was deemed important, to help increase consumer confidence in agri-food nanotechnology, even if there was some scepticism about how well consumers would understand labelling of nanotechnology in agri-food products (see Supplementary Box 4g).

Theme 5: characteristics of food nanotechnology

Acceptance of agri-food nanotechnology appears to be partly determined by the technology underpinning nanotechnology products, product characteristics and the cost of nanotechnology products (see Supplementary Box 5a). Those who preferred foods to be produced using "natural" processing methodologies, and who associated this with being healthy, perceived nanotechnology to be less acceptable, due to greater perceptions of risk. If agri-food nanotechnology brings tangible and concrete advantages to consumers (e.g. in relation to increased food security), then experts are more likely to rate the different applications as acceptable (see Supplementary Box 5b). Consumers were however, not willing to pay more for products developed using nanotechnology, independently of the benefits that will be delivered through its application.

Theme 6: link to historical agri-food technology concerns

In some of the studies reviewed, consumers linked agri-food nanotechnology to GM foods. This may have lowered the acceptability of agri-food nanotechnology if GM foods are perceived negatively (see Supplementary Box 6). Where there was consumer uncertainty about the acceptability of agri-food 
nanotechnology, individuals utilised their existing "reference points" to assess the risks and benefits arising from the technology. As one of these reference points is potentially GM foods, this may have created lower consumer acceptance of agri-food nanotechnology.

Theme 7: marketing and commercialisation

In order to encourage consumer purchases of agri-food nanotechnology products, the role of marketing and, in particular, branding is potentially an important topic of research. Highlighting the benefits to consumers via marketing communications was rated important, as was the development of a "trustworthy brand". These recommendations are not dissimilar to the role marketing plays for other types of products and services (see Supplementary Box 7a).

It was recognised that encouraging increased repeat purchases of agri-food nanotechnology would inspire confidence in other population groups and thus increase acceptance. Thus it was suggested that those consumers who view agri-food nanotechnology to be most acceptable may "lead" in terms of technology adoption, which may then open up the market for other agri-food nanotechnology products (see Supplementary Box 7b). It was also reported that food packaging should be commercialised ahead of foods produced using nanotechnology, as this would be more acceptable to consumers. Furthermore, informed expert opinion might usefully be utilised to facilitate the formation of consumer opinions regarding agri-food nanotechnology and its potential acceptability by consumers.

Theme 8: future applications of agri-food nanotechnology

Most recommendations for future research focused on understanding the determinants of consumer acceptance of food nanotechnology in different cultures. Comparing expert and consumer opinion was considered an important research area, as there may be a mismatch between what experts would provide in terms of agri-food nanotechnology and what would be accepted by consumers (see Supplementary Box 8a). This applied to future developments as well as those currently well advanced in terms of their innovation trajectories.
When consumer characteristics were considered in the studies reviewed, there was a focus on demographic characteristics rather than wider psychographic characteristics. Thus, moving beyond the focus on socio-demographic characteristics and to consider other psychological and cultural determinants was also identified as important (see Supplementary Box 8b). For example, consumers with an internal "health locus of control" (who perceive that they are able to influence their own health status through their behaviours) may be more inclined to adopt consumer products with distinct health benefits (Poínhos et al. 2014).

Exploring the drivers of social negativity towards new technologies, as well as risk aversion in the context of agri-food nanotechnology, were identified as future research priorities (see Supplementary Box 8c). Furthermore, there was a call for consumer acceptance research to use real nanotechnology products, rather than hypothetical scenarios, in order to provide study participants with a real experience of such products. This could help to provide a more realistic evidence base regarding consumer acceptance of nanotechnology, although it is clearly dependent on both the product innovation trajectory and regulatory approval of such products, in particular if they were consumed by study participants, or in some other way come into physical contact with consumers.

Finally, other key issues were identified that might influence consumer acceptance of agri-food nanotechnology. These considerations also related to the themes identified above, particularly providing clear and detailed information, involving multiple stakeholders in the debate on nanotechnology and building consumer confidence and trust (see Supplementary Box 8d).

\section{Discussion}

\section{Statement of main findings}

We believe that this is the first systematic review to explore empirical findings reporting on consumer and expert acceptance of nanotechnology applied to the agri-food sector. Included in this review are 32 empirical studies focused on consumer and expert opinions towards agri-food nanotechnology. The majority of these studies used a survey methodology 
to assess acceptance, although each survey asked very different questions of participants. In-depth empirical (i.e. qualitative research), or experimental research (for example, that which examined the impacts of information interventions on consumer attitudes) exploring consumer acceptance was limited, and it may be useful to follow this up in future research. The analysis of the research reported in the papers included in the review identified eight themes which appear relevant to understanding societal acceptance of agrifood nanotechnology. The consumer studies, and those involving expert assessment of consumer perceptions, suggested that the benefits and risks which consumers perceive to be associated with nanotechnology applied to food production and food products is likely to be an important determinant of consumer responses. In this respect, agri-food nanotechnology is likely to be accepted by consumers if the perceived benefits in some way outweigh the perceived risks and associated consumer concerns. In particular, nanotechnology was deemed more acceptable when it was used in food packaging and processing rather than as an integral part of food products themselves. It was also found that agri-food nanotechnology may be more acceptable if it results in cheaper, safer, consumer products, i.e., a tangible and desirable consumer benefit is delivered as a consequence of its application.

There is reasonable consistency in the literature regarding societal acceptance of agri-food applications of nanotechnology. Although consumers express some concerns about nanotechnology applied to food production per se, less concern is expressed about nanotechnology applied to innovative novel food packaging. However, the consumer rejection of nanotechnology applied to food production, anticipated by some stakeholders, and following consumer reaction to GM applied to food production in some parts of the world, has not been supported by the evidence identified in this review. Increased inputs by consumers into the product development process, when concrete and tangible consumer benefits are being incorporated into specific products, is required to ensure what is being developed is also what consumers want (Raley et al. In Press).

Our systematic review has also highlighted a major gap in the available literature which concerns research which utilises theoretical approaches to understanding societal acceptance of nanotechnology applied to agri- food production. Developing research which is theoretically informed is potentially advantageous insomuch as it may facilitate greater ability to predict consumer's requirements of nanotechnological innovation in the future. Utilising theoretically driven approaches will also enable more systematic comparison of research outcomes across studies (for example, between populations with different characteristics, with respect to societal acceptance of different applications, and analysis of trends on consumer acceptance with time), in particular if a common theoretical or methodological framework or approach is adopted. It is also notable that many of the studies included in the review identified further exploration of the drivers of social negativity towards new technologies, as well as social negativity and risk aversion as future research priorities. Given that one conclusion of this systematic review is that perceived benefit is a relevant and important determinant of consumer behaviour, it will also be important to understand drivers of acceptance and benefit acquisition. It would be useful if future research systematically integrated both risk and benefit perception analyses in the research design, not least because benefit information might usefully be applied to refining the product development trajectory in the future. Commercial success will depend on consumers perceiving tangible and concrete benefits to be associated with the application of nanotechnology to food products.

Strength and weaknesses of studies included in the review

The majority of the studies reviewed used quantitative survey methodologies. Often large-and sometimes nationally representative-samples were used. This facilitated comparative analysis of the acceptance of agri-food nanotechnology across different consumer segments but did not allow for exploration or in-depth analysis of why these views were held by consumers, given the method used to collect the data. Three studies utilised experimental methodologies (i.e. choice experiments) to explore consumer preferences for (hypothetical) food nanotechnology products. Consumer experience (whether positive or negative) of foods produced using nanotechnology may influence subsequent choice behaviours, and as such limit the generalisability of findings from studies using choice experiments. 
In addition, the application of formal quality appraisal indicated that studies were poor at reporting sampling and analytical procedures, and often ethical approvals for research which utilised human participants. However, the studies assessed acceptance of agri-food nanotechnology across a wide range of stakeholders, including representative groups of consumers, experts and commercialisers, as well as reporting data from a cross-section of participants, from multiple countries and backgrounds. Therefore, whilst the findings of this review highlight acceptance of agri-food nanotechnologies from the perspective of multiple stakeholders, further research is required to see how the gap can be narrowed between expert/commercialiser opinions and consumer views, to ensure nanotechnologies are acceptable to consumers, whilst being commercially viable to those who produce such technologies.

\section{Strengths and weaknesses of this review}

We believe that this systematic review has captured the available empirical evidence exploring consumer and expert opinion towards agri-food nanotechnology. Similar findings are reported across the included papers, and so we are confident that we have reached data saturation (Francis et al. 2009) regarding consumer and expert acceptance of agri-food nanotechnology. In particular, this systematic review affords those interested in commercialising nanotechnology with a quick reference guide to consumer and expert opinions towards nanotechnologies when applied to agri-food products and production methods. This review synthesises the factors that both help and hinder food nanotechnology commercialisation and provides suggestions for future research, legislation of nanotechnology and consumer education. By synthesising all of the relevant literature in these areas, this systematic review allows those interested in the field to gain an oversight of these key issues much more quickly than would occur by reading individual papers. Aggregation of the literature in this systematic review allows readers an opportunity to identify key issues, areas of concern and future developments in the field that would not be obtainable by reading individual papers in a stand-alone context.

Whilst the authors are of the opinion that data saturation was reached, 17 papers were excluded because they were unobtainable in English and/or they were unavailable. Likewise, we have not reviewed the grey literature in this area, and so again, we may have missed relevant opinions that have not been published in English language peer-reviewed journals. Some of the papers refer to grey literature, such as the Eurobarometer (European Commission 2010), but they do not discuss themes that are wholly different to the results of our systematic review.

A further weakness is that we have been unable to undertake a quantitative meta-analysis given the heterogeneity of dependent variables across the included papers. However, it may be feasible to revisit this review at a future date to conduct a meta-analysis, once there are a greater number of published empirical studies in this area which report suitable data.

Implications for policy and practice

A consistent finding was that acceptance depends on the perceived benefits of nanotechnology outweighing the perceived risks, although there is less consistency in reporting what constitutes a "desirable benefit" in terms of consumer perceptions. Benefits may refer to generic factors like (cheaper) prices or benefits specific to different agri-food applications. Systematic analysis of what these preferred benefits are, and which consumers want them, is needed. Policy makers and other stakeholders should also be aware that much of the research indicated that, for agri-food nanotechnology to be accepted in the marketplace, consumer confidence and trust in nanotechnology, food manufacturers, regulators and nanotechnology experts, must be developed and maintained. This might be achieved, for example, through good technology governance practice, e.g. (see Bernstein et al. 2014; Marchant 2012), effective risk-benefit communication, (Binder et al. 2011; Frewer et al. 2015) and stakeholder and end-user involvement on technology development, in line with best practice in responsible Research and Innovation policies (de Bakker et al. 2014; von Schomberg 2013).

A focus on communicating the potential benefits and risks of nanotechnology, building on consumer concerns, and investigation of how food nanotechnology can be regulated in a way that inspires consumer confidence, will increase the likelihood of food nanotechnology purchases. 


\section{Conclusion}

Nanotechnology is more likely to be accepted in food packaging rather than integrated into food products. Trust and confidence in agri-food nanotechnology needs to be fostered, to increase consumer acceptance. Providing information to consumers on the benefits of nanotechnology, and ensuring an informed public could help to reduce consumer concern and could inspire food nanotechnology purchases. However, research is needed to understand what consumers perceive as beneficial, as well as how they construe risks. Adopting theoretically underpinned approaches to understanding consumer perceptions and attitudes will facilitate comparative analysis across different groups of consumers, different food nanotechnology applications, and allow assessment of trends in consumer priorities and concerns with time.

Acknowledgments The authors would like to thank Dr. Mary Brennan for her initial input and help with the study. No funding was received for this study.

Author contribution LJF conceived of the study, helped draft the manuscript and provided overall leadership for the research. ELG was responsible for data searching and sifting, data extraction and analysis and drafting of the manuscript. BC was responsible for second sifting and drafting of the manuscript. SK and $\mathrm{CH}$ were responsible for drafting of the manuscript. All authors critically commented on, and approved, the final version of the manuscript.

\section{Compliance with ethical standards}

Conflicts of interest The authors declare that there are no conflict of interests.

Open Access This article is distributed under the terms of the Creative Commons Attribution 4.0 International License (http:// creativecommons.org/licenses/by/4.0/), which permits unrestricted use, distribution, and reproduction in any medium, provided you give appropriate credit to the original author(s) and the source, provide a link to the Creative Commons license, and indicate if changes were made.

\section{References}

Ahmadi M, Ahmadi L (2013) Ethical considerations of nanobiotechnology. J Biomater Tissue Eng 3:335-352. doi:10.1166/jbt.2013.1090

Arnold H (2014) Consumer attitudes to new and emerging food technologies. Food Australia 66:21-23
Barnett-Page E, Thomas J (2009) Methods for the synthesis of qualitative research: a critical review. BMC Med Res Methodol 9:59. doi:10.1186/1471-2288-9-59

Becker S (2013) Nanotechnology in the marketplace: how the nanotechnology industry views risk. J Nanopart Res 15:1-13. doi:10.1007/s11051-013-1426-7

Bernstein M, Foley R, Bennett I (2014) An operationalized postnormal science framework for assisting in the development of complex science policy solutions: the case of nanotechnology governance. J Nanopart Res 16:1-14. doi:10. 1007/s11051-014-2492-1

Besley J, Kramer V, Priest S (2008) Expert opinion on nanotechnology: risks, benefits, and regulation. J Nanopart Res 10:549-558. doi:10.1007/s11051-007-9323-6

Bieberstein A, Roosen J, Marette S, Blanchemanche S, Vandermoere F (2013) Consumer choices for nano-food and nano-packaging in France and Germany. Eur Rev Agric Econ 40:73-94. doi:10.1093/erae/jbr069

Binder AR, Cacciatore MA, Scheufele DA, Shaw BR, Corley EA (2011) Measuring risk/benefit perceptions of emerging technologies and their potential impact on communication of public opinion toward science 1-18. Public Underst Sci. doi:10.1177/0963662510390159

Black LJ, Seamans KM, Cashman KD, Kiely M (2011) Efficacy of food fortification for the prevention of vitamin D deficiency_results of a systematic review and meta-analysis. Proceedings of the Nutrition Society 70:E101. doi:10. 1017/S0029665111001418

Braun V, Clarke V (2006) Using thematic analysis in psychology. Qual Res Psychol 3:77-101. doi:10.1191/147808870 6qp063oa

Brown J, Kuzma J (2013) Hungry for information: public attitudes toward food nanotechnology and labeling. Rev Policy Res 30:512-548. doi:10.1111/ropr.12035

Brown J, Fatehi L, Kuzma J (2015) Altruism and skepticism in public attitudes toward food nanotechnologies. J Nanopart Res. doi:10.1007/s11051-015-2926-4

Burri R, Bellucci S (2008) Public perception of nanotechnology. J Nanopart Res 10:387-391. doi:10.1007/s11051-0079286-7

Capon A, Gillespie J, Rolfe M, Smith W (2015) Comparative analysis of the labelling of nanotechnologies across four stakeholder groups. J Nanopart Res. doi:10.1007/s11051015-3129-8

Casolani N, Greehy GM, Fantini A, Chiodo E, McCarthy MB (2015) Consumer perceptions of nanotechnology applications in Italian wine. Italian J Food Sci 27:221-235

Centre for Reviews and Dissemination (2012) About the databases. http://www.crd.york.ac.uk/crdweb/AboutPage.asp. Accessed 13 July 2012

Cheng TJ, Lin YP, Li YR, Chou GT (2009) The risk perception of nanotechnology in Taiwanese general population, workers, and experts. Epidemiol 20:S227-S227. doi:10. 1097/01.ede.0000362761.53798.a8

Cobb M, Macoubrie J (2004) Public perceptions about nanotechnology: risks, benefits and trust. J Nanopart Res 6:395-405. doi:10.1007/s11051-004-3394-4

Conti J, Satterfield T, Harthorn BH (2011) Vulnerability and social justice as factors in emergent U.S. nanotechnology risk perceptions. Risk Anal 31:1734-1748. doi:10.1111/j. 1539-6924.2011.01608.x 
Cook AJ, Fairweather JR (2007) Intentions of New Zealanders to purchase lamb or beef made using nanotechnology. $\mathrm{Br}$ Food J 109:675-688. doi:10.1108/00070700710780670

Critical Appraisal Skills Programme (2013) 10 questions to help you make sense of qualitative research. http://www.caspuk.net/\#!casp-tools-checklists/c18f8. Accessed 12 Nov 2015

de Bakker E, de Lauwere C, Hoes A-C, Beekman V (2014) Responsible research and innovation in miniature: information asymmetries hindering a more inclusive 'nanofood' development. Sci Public Policy 41:294-305. doi:10.1093/ scipol/scu033

European Commission (2010) Biotechnology. http://ec.europa. eu/public_opinion/archives/ebs/ebs_341_en.pdf. Accessed 11 Nov 2015

Farshchi P, Sadrnezhaad S, Nejad N, Mahmoodi M, Ibrahimi Ghavam Abadi L (2011) Nanotechnology in the public eye: the case of Iran, as a developing country. J Nanopart Res 13:3511-3519. doi:10.1007/s11051-011-0274-6

Francis JJ, Johnston M, Robertson C, Glidewell L, Entwistle V, Eccles MP, Grimshaw JM (2009) What is an adequate sample size? Operationalising data saturation for theorybased interview studies. Psychol Health 25:1229-1245. doi:10.1080/08870440903194015

Frewer LJ, Norde W, Fischer A, Kampers F (2011) Nanotechnology in the agri-food sector. Wiley, Weinheim

Frewer LJ, Fischer AR, Brennan M, Banati D, Lion R, Meertens RM, Rowe G, Siegrist M, Verbeke W, Vereijken CM (2015) Risk/benefit communication about food-a systematic review of the literature. Critical Rev Food Sci Nutr. doi:10.1080/10408398.2013.801337

George S, Kaptan G, Lee J, Frewer L (2014) Awareness on adverse effects of nanotechnology increases negative perception among public: survey study from Singapore. J Nanopart Res 16:1-11. doi:10.1007/s11051-014-2751-1

Grobe A, Renn O, Jaeger A (2008) A report for IRGC risk governance of nanotechnology applications in foods and dosmetics. International Risk Governance Council, Geneva

Groves C (2013) Four scenarios for nanotechnologies in the UK, 2011-2020. Tech Analy Strat Manag 25:507-526. doi:10. 1080/09537325.2013,785510

Gupta N, Fischer ARH, Frewer LJ (2011) Socio-psychological determinants of public acceptance of technologies: a review. Public Underst Sci. doi:10.1177/0963662510392485

Gupta N, Fischer AR, van der Lans IA, Frewer LJ (2012) Factors influencing societal response of nanotechnology: an expert stakeholder analysis. J Nanopart Res 14:857. doi:10.1007/ s11051-012-0857-x

Gupta N, Fischer AH, George S, Frewer L (2013) Expert views on societal responses to different applications of nanotechnology: a comparative analysis of experts in countries with different economic and regulatory environments. J Nanopart Res 15:1-15. doi:10.1007/s11051-013-1838-4

Gupta N, Fischer ARH, Frewer LJ (2015) Ethics, risk and benefits associated with different applications of nanotechnology: a comparison of expert and consumer perceptions of drivers of societal acceptance. Nanoethics 9:93-108. doi:10.1007/s11569-015-0222-5

Handford CE, Dean M, Spence M, Henchion M, Elliott CT, Campbell K (2015) Awareness and attitudes towards the emerging use of nanotechnology in the agri-food sector. Food Control 57:24-34. doi:10.1016/j.foodcont.2015.03. 033

Kim Y-R, Lee EJ, Park SH, Kwon HJ, An SSA, Song SW, Pie JE, Yoon M, Kim JH, Kim MK (2014) Comparative analysis of nanotechnology awareness in consumers and experts in South Korea. Int J Nanomed 9:21-27. doi:10. 2147/IJN.S57921

Köhler AR, Som C (2008) Environmental and health implications of nanotechnology-have innovators learned the lessons from past experiences? Human Ecol Risk Assess Int J 14:512-531. doi:10.1080/10807030802071812

Lin YP, Li YR, Chou KT, Cheng TJ (2011) Public perceptions of nanotechnology in Taiwan. Epidemiol 22:S67-S67. doi:10.1097/01.ede.0000391869.09804.be

Lowe P, Murdoch J, Marsden T, Munton R, Flynn A (1993) Regulating the new rural spaces: the uneven development of land. J Rural Stud 9:205-222. doi:10.1016/07430167(93)90067-T

Macoubrie J (2006) Nanotechnology: public concerns, reasoning and trust in government. Public Underst Sci 15:221-241. doi:10.1177/0963662506056993

Marchant GE, Abbott KW (2012) International harmonization of nanotechnology governance through soft law approaches. Nanotech Law Bus. doi:10.2202/1941-6008.1120

Marette S, Roosen J, Bieberstein A, Blanchemanche S, Vandermoere F (2009) Impact of environmental, societal and health information on consumers' choices for nanofood. J Agric Food Ind Org. doi:10.2202/1542-0485.1274

Matin AH, Goddard E, Vandermoere F, Blanchemanche S, Bieberstein A, Marette S, Roosen J (2012) Do environmental attitudes and food technology neophobia affect perceptions of the benefits of nanotechnology? Int J Consum Stud 36:149-157. doi:10.1111/j.1470-6431.2011. 01090.x

Mehta MD (2004) From biotechnology to nanotechnology: what can we learn from earlier technologies? Bull Sci Tech Soc 24:34-39. doi:10.1177/0270467604263119

Militaru G, Ionescu S (2013) An examination of whether and how can reduce the barriers to nanotechnology transfer: a conceptual approach. Metalurgia Int 18:150-154

Mir L (2007) Perception of the dangers of nanotechnologies by experts and the uninformed. Environ Risques Sante 6:331-332

Moher D, Liberati A, Tetzlaff J, Altman DG, The Prisma Group (2009) Preferred reporting items for systematic reviews and meta-analyses: the PRISMA Statement. PLoS Med 6:e1000097. doi:10.1371/journal.pmed.1000097

Petticrew M, Roberts H (2006) Systematic reviews in the social sciences: a practical guide. Blackwell Publishing, Oxford

Pidgeon N, Harthorn B, Satterfield T (2011) Nanotechnology risk perceptions and communication: emerging technologies, emerging challenges. Risk Anal 31:1694-1700. doi:10.1111/j.1539-6924.2011.01738.x

Poínhos R, van der Lans IA, Rankin A, Fischer ARH, Bunting B, Kuznesof S, Stewart-Knox B, Frewer LJ (2014) Psychological determinants of consumer acceptance of personalised nutrition in 9 European countries. PLoS One 9:e110614. doi:10.1371/journal.pone.0110614

PROPSERO (2012) About PROSPERO. http://www.crd.york. ac.uk/PROSPERO/. Accessed 12 Nov 2015 
Rakia N (1993) Becoming clear. Integration 35:14-15

Raley MA, Ragona MA, Sijtsema SJ, Fischer ARH, Frewer LJ (2015) Barriers to using consumer science information in food technology innovations: An exploratory study using Delphi methodology. Int J Food Sci Tech

Renn O, Roco MC (2006) Nanotechnology and the need for risk governance. J Nanopart Res 8:153-191. doi:10.1007/ s11051-006-9092-7

Roco MC (2003) Broader societal issues of nanotechnology. J Nanopart Res 5:181-189. doi:10.1023/A:1025548512438

Rogers WA, Mitzner TL, Boot WR, Charness N, Czaja SJ, Fisk AD, Sharit J (2013) Predicting technology acceptance through individual differences and perceptions of usefulness and ease of use. Gerontologist 53:226

Roosen J, Bieberstein A, Marette S, Blanchemanche S, Vandermoere F (2011) The effect of information choice and discussion on consumers' willingness-to-pay for nanotechnologies in food. J Agric Res Economics 36:365-374

Roosen J, Bieberstein A, Blanchemanche S, Goddard E, Marette S, Vandermoere F (2015) Trust and willingness to pay for nanotechnology food. (Special Section: consumer and trust: empirical investigations on the outcomes of consumer trust in food.). Food Policy 52:75-83. doi:10.1016/j. foodpol.2014.12.004

Schiffeler J (2014) Harmony of technology and consumer expectations-the influence of published opinion has an impact on a product. Fleischwirtschaft 94:3

Schnettler B, Crisóstomo G, Mills N, Miranda H, Mora M, Lobos G, Grunert KG (2013a) Preferences for sunflower oil produced conventionally, produced with nanotechnology or genetically modified in the Araucanía Region of Chile. Ciencia e Investigación Agraria 40:17-29. doi:10.4067/ S0718-16202013000100002

Schnettler B, Crisóstomo G, Sepúlveda J, Mora M, Lobos G, Miranda H, Grunert KG (2013b) Food neophobia, nanotechnology and satisfaction with life. Appetite 69:71-79. doi:10.1016/j.appet.2013.05.014

Schnettler B, Crisóstomo G, Mora M, Lobos G, Miranda H, Grunert KG (2014) Acceptance of nanotechnology applications and satisfaction with food-related life in southern Chile. Food Sci Tech (Campinas) 34:157-163. doi:10. 1590/S0101-20612014005000001

Scholl G (2013) Consumer conference on the perception of nanotechnology in the areas of food, cosmetics, and textiles, Germany. In. Pan Stanford Publishing Pte. Ltd., pp 57-69. doi:10.4032/9789814364348

Seifert F, Plows A (2014) From anti-biotech to nano-watch: early risers and spin-off campaigners in Germany, the UK and internationally. NanoEthics 8:73-89. doi:10.1007/ s11569-014-0189-7

Siegrist M (1999) A causal model explaining the perception and acceptance of gene technology. J Appl Soc Psychol 29:2093-2106. doi:10.1111/j.1559-1816.1999.tb02297.x

Siegrist M (2007) Consumer attitudes to food innovation and technology. In: MacFie H (ed) Consumer-Led Food Product Development. Woodhead Publishing in Food Science Technology and Nutrition 144: 122-138. doi:10.1533/ 9781845693381.1.122

Siegrist M, Cvetkovich G (2000) Perception of hazards: the role of social trust and knowledge. Risk Anal 20:713-719. doi:10.1111/0272-4332.205064
Siegrist M, Cousin M-E, Kastenholz H, Wiek A (2007) Public acceptance of nanotechnology foods and food packaging: the influence of affect and trust. Appetite 49:459-466. doi:10.1016/j.appet.2007.03.002

Siegrist M, Stampfli N, Kastenholz H, Keller C (2008) Perceived risks and perceived benefits of different nanotechnology foods and nanotechnology food packaging. Appetite 51:283-290. doi:10.1016/j.appet.2008.02.020

Siegrist M, Stampfli N, Kastenholz H (2009) Acceptance of nanotechnology foods: a conjoint study examining consumers' willingness to buy. Br Food J 111:660-668. doi:10.1108/00070700910972350

Simons J, Zimmer R, Vierboom C, Härlen I, Hertel R, Böl G-F (2009) The slings and arrows of communication on nanotechnology. J Nanopart Res 11:1555-1571. doi:10.1007/ s11051-009-9653-7

Stampfli N, Siegrist M, Kastenholz H (2010) Acceptance of nanotechnology in food and food packaging: a path model analysis. J Risk Res 13:353-365. doi:10.1080/13669870903233303

Stone JV (2009) Public perceptions of agrifood nanotechnologies: using extension to assess and link stakeholder knowledge with public policies. Abstr Pap Am Chem Soc 237:125

Suerdem AK, Gumus B, Unanoglu M Determinants of risk perception towards science and technology. In: Istanbul, 2013. 4th international conference on risk analysis and crisis response, RACR 2013. pp 777-783

Suhaimee S, Serin T, Ali AK, Sulaiman NH, Ghazali Z (2014) Public awareness and perception of nanotechnology among Malaysian. World Applied Sciences Journal 31:367-375

Tanaka Y (1995) The major factors promoting public acceptance of a variety of technologies. Jpn J Exp Soc Psychol 35:111-117

Teggatz JL (2013) Scholarly and public views: Understanding narratives around nanotechnology. Dissertation Abstracts International Section A: Humanities and Social Sciences 74

Thompson P (n.d.) The ethics of getting small. Agricultural Experiment Station, Michigan State University, East Lansing

Thoenes HW (1982) Risk acceptance in technology and society. Stahl Eisen 102:1029-1032

van Broekhuizen P, Reijnders L (2011) Building blocks for a precautionary approach to the use of nanomaterials: positions taken by trade unions and environmental NGOs in the European nanotechnologies debate. Risk Anal 31:16461657. doi:10.1111/j.1539-6924.2011.01615.x

von Schomberg R (2013) A vision of responsible research and innovation. In: Responsible Innovation. Wiley, pp 51-74. doi:10.1002/9781118551424.ch3

Yawson RM, Kuzma J (2010) Systems mapping of consumer acceptance of agrifood nanotechnology. J Consum Policy 33:299-322

Yue C, Zhao S, Cummings C, Kuzma J (2015a) Investigating factors influencing consumer willingness to buy GM food and nano-food. J Nanopart Res. doi:10.1007/s11051-015-3084-4

Yue CY, Zhao SL, Kuzma J (2015b) Heterogeneous consumer preferences for nanotechnology and genetic-modification technology in food products. J Agric Econ 66:308-328. doi:10.1111/1477-9552.12090

Zimmer R (2008) Nanotechnology and public opinion-the perception of innovative technology. Nanotechnologie: Grundlagen, Anwendungen, Risiken, Regulierung. doi:10. 1515/9783899496192.3.93 